\title{
Vessel Target Prediction Method and Dead Reckoning Position Based on SVR Seaway Model
}

\section{Joo-Sung Kim}

Kyeong-In VTS Center, Korea Coast Guard, Incheon, Korea

\section{]jfis}

Received: Nov. 30, 2017

Revised : Dec. 17, 2017

Accepted: Dec. 18, 2017

Correspondence to: Joo-Sung Kim

(jskim81@korea.kr)

(CThe Korean Institute of Intelligent Systems

cc) This is an Open Access article distributed under the terms of the Creative Commons Attribution Non-Commercial License (http://creativecommons.org/licenses/ by-nc/3.0// which permits unrestricted noncommercial use, distribution, and reproduction in any medium, provided the original work is properly cited.

\begin{abstract}
A person who has responsible for ship's safety, such as captain and Vessel Traffic Service Operator (VTSO), should make a decision to prevent the ship from colliding or other accident related on traffic situation. At this time, the positions of the own ship and the opponent ship are used for identification and prediction of the future situation, and the action is selected based on this information. Here, the person in charge predicts the position of itself and the opposing ship, and the calculated positions are called Dead Reckoning Position (DRP). In the existing DRP calculation, the position of the ship is predicted based on the current position, speed and course, so it cannot be applied in all navigation situations. For this reason, both the vessel and the VTS center utilize the navigation intentions of the two vessels related to the traffic situation for their own decision-making. In this study, we intend to predict the ship's position based on the route extraction method proposed in the SVR seaway model. We predict the future speed, and propose a method of predicting the position applied to the SVR seaway model. For the verification of the proposed DRP calculation, a virtual path and ship's trajectories which are similar to the actual navigation environment were constructed. As a result, comparison data between the existing DRP and proposed DRP are presented. And enhanced closest point of approach calculation results are presented for two approaching ships as a time series. We expect that the advanced DRP could be used for relevant tasks to ship's mater and/or VTSO.
\end{abstract}

Keywords: Vessel Traffic Services, Dead reckoning position, Seaway model, Support vector regression, Machine learning

\section{Introduction}

Recently, the environment of marine traffic conflicts with the use of limited marine space and the aspect of traditional ship's navigation. In terms of the sharing and utilization of restricted marine space, the space of coastal area has been saturated for using development of clean energy, exploitation of marine resources and collection of fish resources [1. 2]. In addition, in terms of ship's marine traffic environment, further technics and analyses are required to avoid marine accidents due to popularizing huge and high speed vessels [3, 4]. Therefore, in order to avoid these marine accidents and maximize the effectiveness of marine traffic, vessels which navigate within harbor limits and approaching areas should follow the designated traffic routes. At the same time, the authorized governments operate Vessel Traffic Service (VTS) for the reasons mentioned above. Meanwhile, VTS has established based on 'IMO RESOLUTION 
A.857(20) on Guidelines for Vessel Traffic Services', Article 36 of 1Maritime Safety Act', Chapter 4 of 'Act of Ship Arrival and Departure' and 'rules of implementation for Vessel Traffic Services' [5-8].

When a traffic situation occurs during navigation in a limited area, the masters or ship's officers identify the positions of own vessel and the opponent. Based on these positions, the future situations can be predicted and the action to be taken to prevent any accident would be determined. At this time, the positions that obtained from the calculation result are called Dead Reckoning Position (DRP) [9]. The prediction of DRPbased traffic situation is an important factor for determining of the operation for prevention of collision. In the same way, VTS Operator (VTSO) also predicts the positions of all ships in a VTS area [10]. However, in the existing DRP calculation, the position of the ship is predicted based on the current position, speed and course of the ship. Therefore, it could not be applied in all navigation situations and all areas [10]. For this reason, both the vessel and the VTS center determine their own decision making through navigation intentions of the two vessels related to the traffic situation.

In this study, we intend to predict the ships' positions based on the SVR seaway model that proposed previously. Based on the route extraction method proposed in the SVR seaway model, we predict the future speed through data learning from the speed data of the ship and propose a method of predicting the position applied to the SVR seaway model. In order to verify the proposed DRP calculations, we construct a virtual path and ships' trajectories that similar to the actual navigation environment for simulations. We present the results of the DRP calculation and the comparison data between existed and proposed DRP calculation. In addition, we compare the results of the proposed CPA calculation method and the existed method for two approaching vessels in order to verify the performance.

\section{SVR Seaway Model}

There are several factors that determine ship's navigational route such as condition of the ship or navigational environment of the ship. In port areas and approaching waters, ships' tracks appear in a specific pattern depending on the commenced and completed points of a journey. Especially, vessel target prediction method that proposed in this paper is based on the ship's traffic pattern. Therefore the pattern recognition of ship's traffic and presentation are the main factors for the target prediction. In this study, SVR seaway model proposed by Kim and Jeong [11, 12] was used to predict the position of the ship. The SVR seaway model is a method of extracting the trajectory model as a result of learning the data set which are pre-collected and processed using the SVR [11, 12]. It is known that this method can be applied to the navigational environment where the marine traffic environment is complicated such as in the port and adjacent waters because the extracted traffic route model is defined based on the individual navigational data of the ships. The feature of data learning through SVR is to select the number of Support Vectors (SV) to be learned according to the selected parameters to determine the output model [11, 12]. Thus, the output model via SVR can extract the route model without being limited by the size of the data set of the vessel being studied. Because of this feature, the SVR seaway model is suitable for applying to the port waters with frequent changes of the navigation pattern due to the port development, the change of the navigational environment and so on. In addition, since the navigational pattern can be analyzed using only the navigational data set for a specific period designated by the user and the result of the navigational data learning can be outputted. Therefore, the traffic model reflecting the characteristics of the specific period can be extracted [11, 12].

While the traditional pattern recognition techniques are based on empirical risk minimization methods using statistical pattern recognition methods according to the distribution pattern of the data, SVR minimizes the error probability for the data with fixed but unknown probability distributions which is based on structural risk minimization [13-16]. The grid search technique using v-fold cross validation is used in order to select the kernel functions and the optimal parameters which are most important parts to construct the SVR model for extracting the navigational patterns. This technique is highly reliable in the LIBSVM algorithm proposed by Hsu et al. [17], and it is widely used to construct optimal parameter combinations in various data learning algorithms.

The procedure for extracting the traffic models is as shown in Figure 1. The collected data is classified into the area for learning according to the target sea area and classified into the individual data of the ship through the logical search. Individual ship data is converted into a data structure for learning and stored, and the constructed database is classified according to the sailing section of the ship to form a data set for each ship according to the individual sailing. For each ship's navigational data classified according to the navigational section, the way points are extracted through the curvature discrimination and the curve sections are defined. The data set for learning is composed 


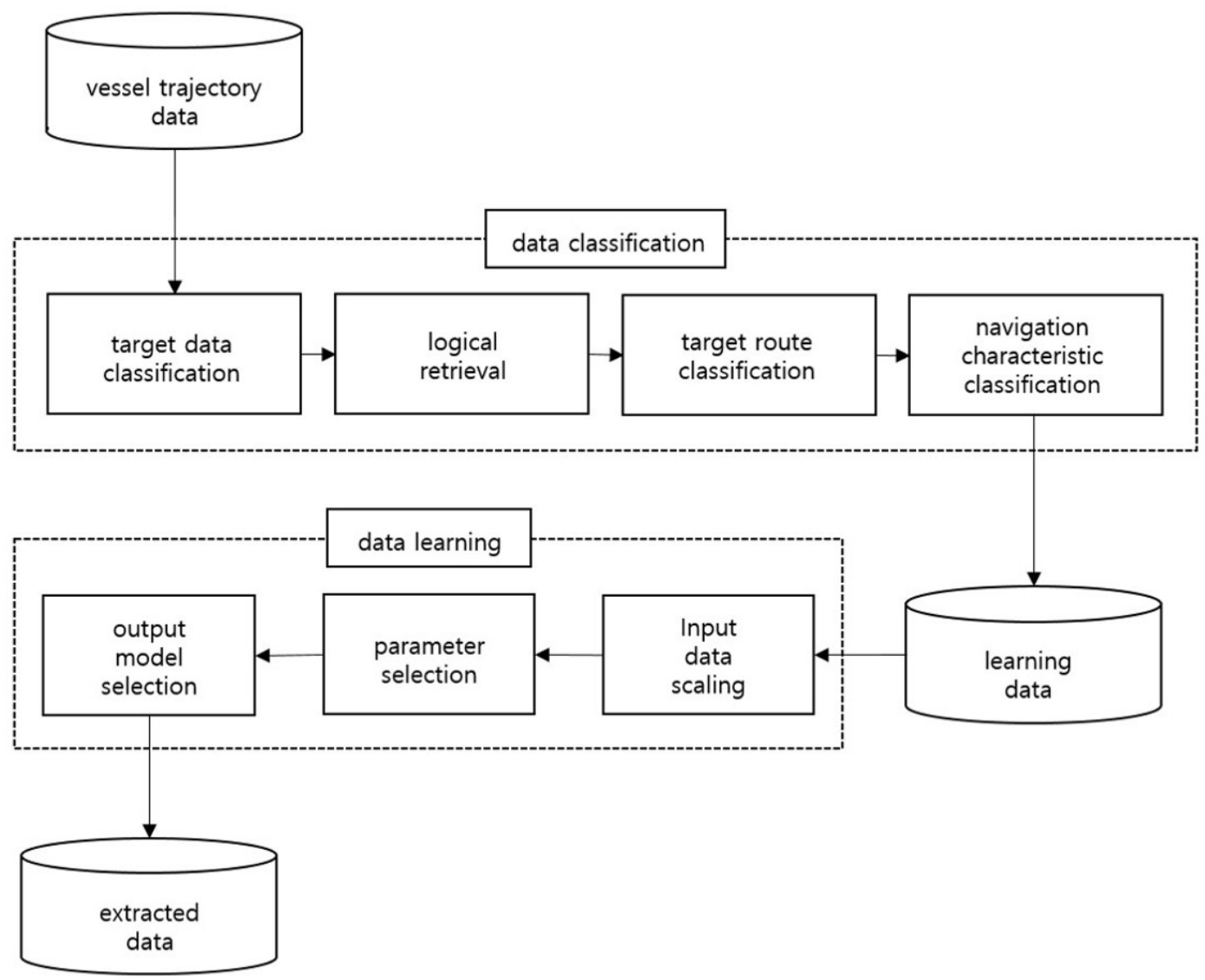

Figure 1. Data process procedure of SVR seaway model.

by constructing a lower data set according to a defined curve section. The output trajectory models of the lower data set are sorted based on position and the entire learning is performed again. Finally, the final trajectory model is extracted as a result of the learning. The output model based on each individual leg extracted through this process is defined as the representative model of each leg and a database of the extracted traffic model is constructed.

\section{Target Prediction Method}

The DRP is the position of the ship that determined by the following calculation with the speed and course of the ship based on the current position of the ship or the position of the specific time at which the position was measured [9]. In vessel practice or VTS practice, it is not necessary to take account of other marine environment factors such as tidal steam or wind direction because it can be calculated and displayed in real time through Automatic Radar Plotting Aids (ARPA). The DRP was used to estimate the current position of the ship when the position was measured by stars or by using LORAN$\mathrm{C}$ (long range navigation $\mathrm{C}$ ). However, in modern nautical navigation, DRP is used to predict the navigational relationship with other vessels and the situation when the ship is encountered or considered dangerous situations in traffic. In addition, DRP is used to know the position of own ship or the other ship's position after a certain time. However, there is a limitation in estimating the position because current DRP calculation is based on the current position, speed, and course of the ship [10]

Figure 2 is a simplified illustration of the current DRP calculation method and the proposed DRP calculation method. Kim et al. [18] proposed a position estimation based on the traffic extraction model in the related paper. It is a method of estimating the position based on the navigation data of the ship navigating along a specific route and the route data to be navigated in the future as shown in Figure 2(b) [18, 19].

The position estimation based on the traffic model is more effective than the current DRP calculation method in predicting the ship's position when navigating along a specific route [10]. The most important thing in this method is how to reconstruct 

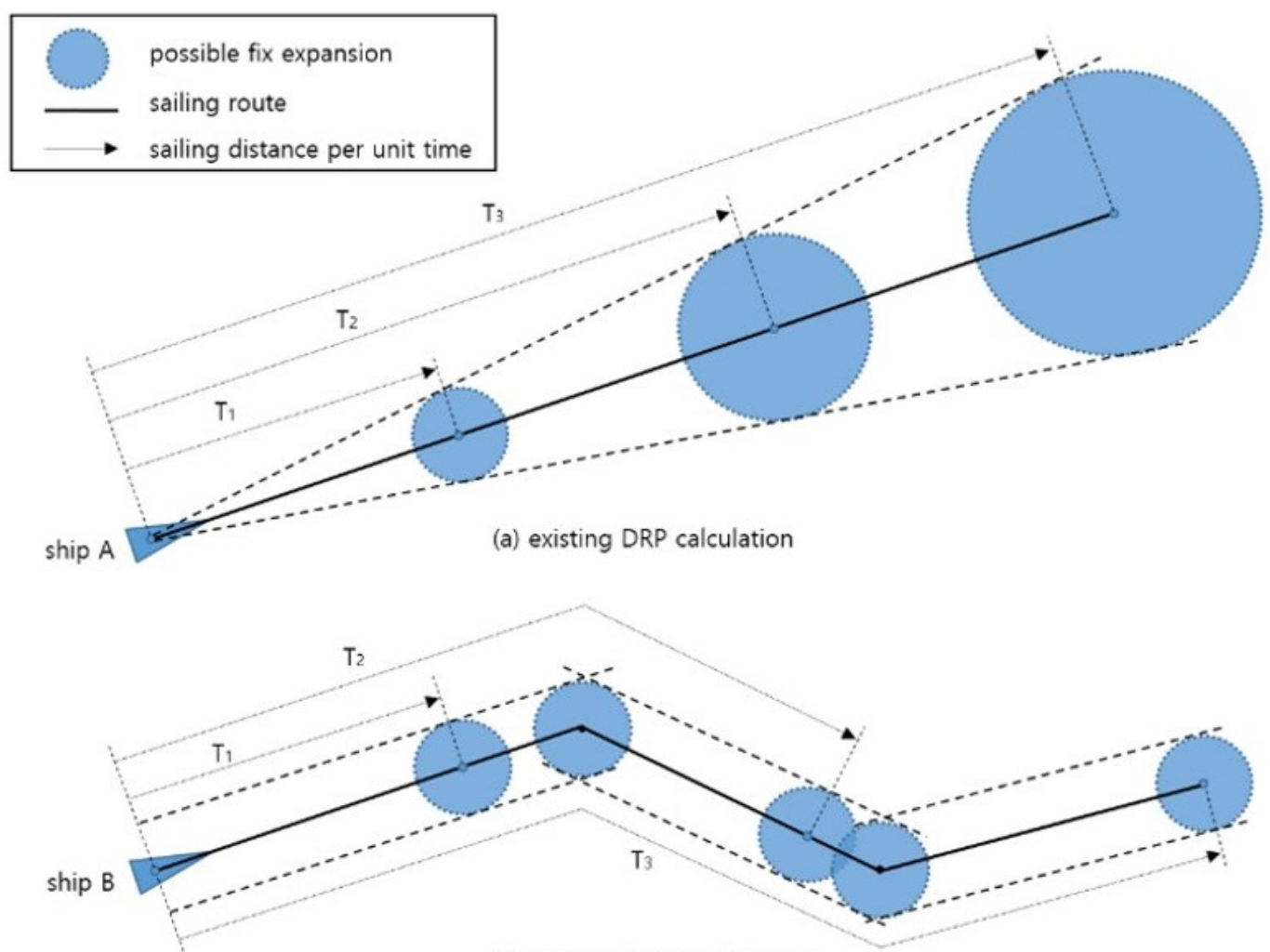

(b) proposed DRP calculation

Figure 2. Concept of DRP calculations. (a) Existing and (b) proposed DRP calculation.

the traffic route. In addition to the planned route provided by the ship, it is important to reconstruct the reliable route data. The method of predicting the position by using the reconstructed trajectory by the expert group or the planned route provided by the ship and the method using only the traffic model predicts the position based on the present speed. These methods cannot cope with speed changes in calculation. Therefore, in this paper, we intend to utilize SVR seaway model which is a method of extracting the ship's traffic route, and DRP can be derived by applying the traffic pattern and the pattern of speed changes. The proposed method learns the pattern of speed changes for each position of the ship and shows the DRP on the traffic model according to the change of the speed from the current position to the destination and the position after time aiming. Therefore, in the proposed method, it is possible to estimate the position more accurately than the method using only the traffic model, even if the ship is accelerating or decelerating. Because the proposed method reflects the specific pattern of the navigational data such as position, speed and course. Table 1 describes each feature according to the method of DPR calculation.

The position estimation based on SVR seaway model is basi-
Table 1. Differences of DRP calculations

\begin{tabular}{|c|c|c|c|}
\hline $\begin{array}{c}\text { Current DRP } \\
\text { DRP based on } \\
\text { Proposed DRP }\end{array}$ & Position criteria & Speed & Course \\
\hline $\begin{array}{l}\text { Current DRP } \\
\text { calculation }\end{array}$ & $\begin{array}{l}\text { Current } \\
\text { position }\end{array}$ & $\begin{array}{l}\text { Current } \\
\text { speed- } \\
\text { based }\end{array}$ & $\begin{array}{c}\text { Current } \\
\text { course- } \\
\text { based }\end{array}$ \\
\hline $\begin{array}{l}\text { DRP based on } \\
\text { planned route } \\
\text { only }\end{array}$ & $\begin{array}{l}\text { Current } \\
\text { position }\end{array}$ & $\begin{array}{l}\text { Current } \\
\text { speed- } \\
\text { based }\end{array}$ & $\begin{array}{l}\text { Planned } \\
\text { course- } \\
\text { based }\end{array}$ \\
\hline $\begin{array}{l}\text { Proposed DRP } \\
\text { calculation }\end{array}$ & $\begin{array}{l}\text { Current } \\
\text { position }\end{array}$ & $\begin{array}{l}\text { Learned } \\
\text { and } \\
\text { predicted } \\
\text { speed- } \\
\text { based }\end{array}$ & $\begin{array}{l}\text { Learned } \\
\text { and } \\
\text { predicted } \\
\text { course- } \\
\text { based }\end{array}$ \\
\hline
\end{tabular}

cally on the basis of accurate and reliable trajectories. Therefore, the traffic model is derived from the SVR seaway model and the following procedure is performed to construct the SVR seaway model based location estimation algorithm.

First, extracted traffic model was selected through data learning.

Second, the navigational data model was constructed through 


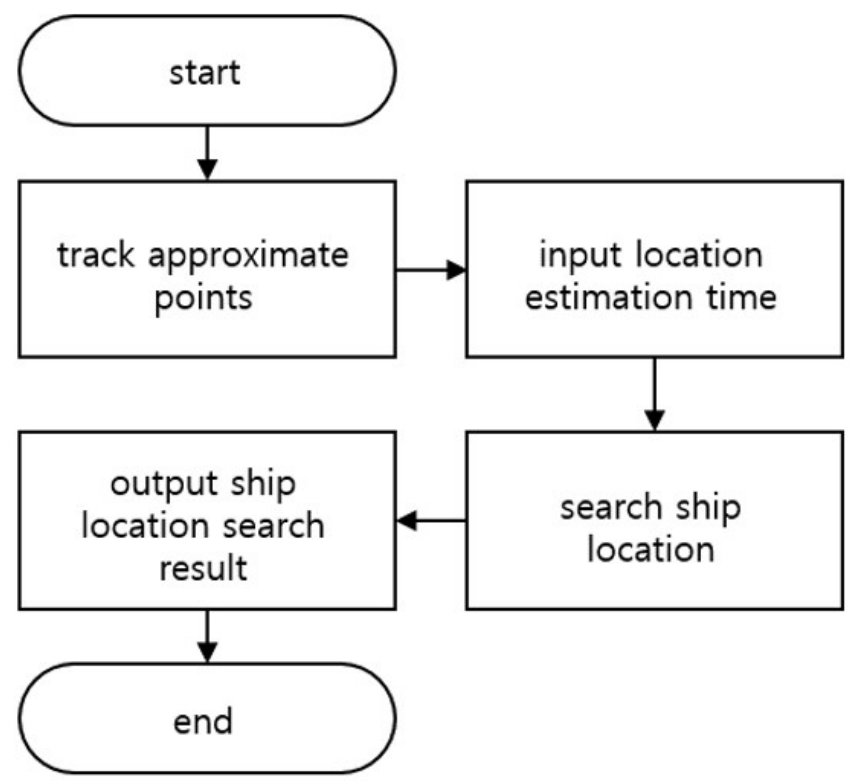

Figure 3. Ship's location tracking process.

the learning of the speed and course data according to the ship's positions.

Third, the approximate point of the trajectory extracted traffic model is searched according to the current position of the vessel.

Fourth, the predicted navigational distance reflecting the speed pattern and the current speed of the ship was calculated.

Fifth, the estimated position is shown on the traffic route by performing the preliminary estimation according to the predicted navigational distance from the approximation point of the extracted traffic model obtained through the navigation search.

Figure 3 is the flow chart for explaining how to predict the position of the ship. Firstly, an approximate point is calculated which is the minimum difference between the extracted traffic model and the current position of the target vessel. The approximate point is on the extracted traffic model calculated by the SVR seaway model based on the navigational data of the target vessel. Enter the input value for the position estimation time for the target ship. The position of the target ship is estimated after the predetermined time corresponding to the input value for the position estimation time which has elapsed from the current time. The estimated position is based on the navigational data provided in the calculated section of the traffic model from the calculated approximate point. At this time, the position data, the speed data, and the course data are applied to the position data, the speed data, and course data of the approximate points to predict the position of the target vessel. The predicted vessel position is shown and compared with the vessel's current loca- tion, traffic model and traditional calculation to help the user's objective decision-making.

Meanwhile, when both vessels approach and navigate gradually, it is defined as the position of ship $A(x, y)$, the course $\theta$, the speed $v$ and the relative ship's position, speed and course $x_{1}$, $y_{1}, \theta_{1}, v_{1}$. To estimate the Closest Point of Approach (CPA), the time to CPA (TCPA), TCPA $\left(t_{\min }\right)$ of the two vessels are calculated. Here, assuming that the ships are constant in speed and course at the given time $t=0$, the distance between two ships is given by the following equation (1] [20]:

$$
\begin{aligned}
& d s i t^{2}(\theta, v, t)=a_{2} t^{2}+a_{1} t+a_{0}, \\
& a_{2}=\cos ^{2}(\theta) v^{2}-2 \cos (\theta) v \cos \left(\theta_{1}\right) v_{1} \\
& +\cos ^{2}\left(\theta_{1}\right) v_{1}^{2}+\sin ^{2}(\theta) v^{2} \\
& -2 \sin (\theta) v \sin \left(\theta_{1}\right) v_{1}+\sin ^{2}\left(\theta_{1}\right) v_{1}^{2}, \\
& a_{1}=2 \cos (\theta) v y-2 \cos (\theta) v y_{1} \\
& -2 y \cos \left(\theta_{1}\right) v_{1}+2 \cos \left(\theta_{1}\right) v_{1} y_{1} \\
& +2 \sin (\theta) v x-2 \sin (\theta) v x_{1} \\
& -2 x \sin \left(\theta_{1}\right) v_{1}+2 \sin \left(\theta_{1}\right) v_{1} x_{1}, \\
& a_{0}=y^{2}-2 y y_{1}+y_{1}^{2}+x^{2}-2 x x_{1}+x_{1}^{2} \text {, } \\
& C P A(\theta, v, t)=\sqrt{a_{2} t_{\text {min }}^{2}+a_{1} t_{\text {min }}+a_{0}} \text {. }
\end{aligned}
$$

The time TCPA $\left(t_{\min }\right)$ which is the time when the distance between two ships becomes minimum, is calculated by taking the value $T C P A\left(t_{\min }\right)=-a_{1} 2 a_{2}$ which is the value obtained by differentiating the equation (1) that is the distance becomes zero. Therefore, the final equation for CPA estimation can be expressed as the equation (2).

\section{Simulation}

In general, the trajectories of ships that are navigating along the designated route are constructed as shown in Figure 4(a). The result of extracting the traffic model according to the SVR seaway model is shown in Figure 4(b). According to the data learning method presented in the SVR seaway model, the model of the ships' course and speed changes are extracted as shown in Figures 4(c) and 4(d), respectively.

Figure 5 shows the result of each DRP calculation method in order to compare DRP calculation with the traditional calculation method and the proposed method that is using the extracted navigational model. We selected an arbitrary ship among the ships constituting the navigational data set and compared the position estimating results every minute. In the traditional DRP 


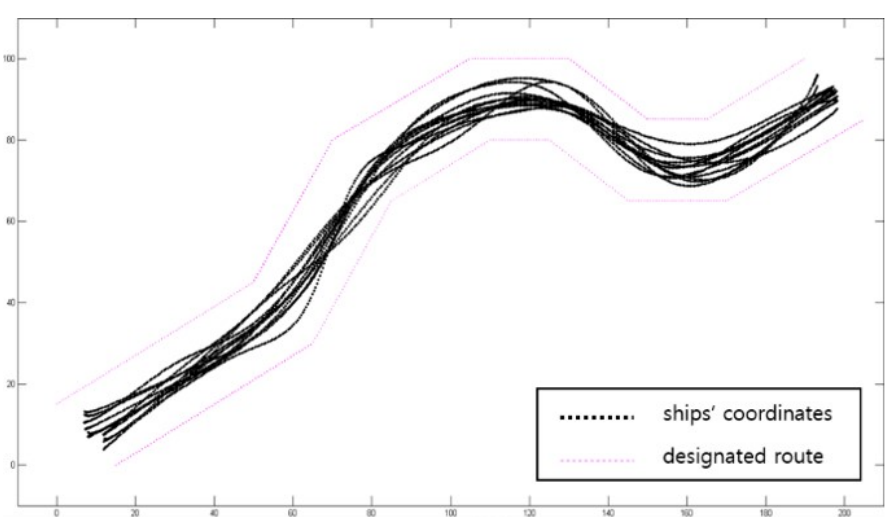

(a) Ship trajectories and designated route

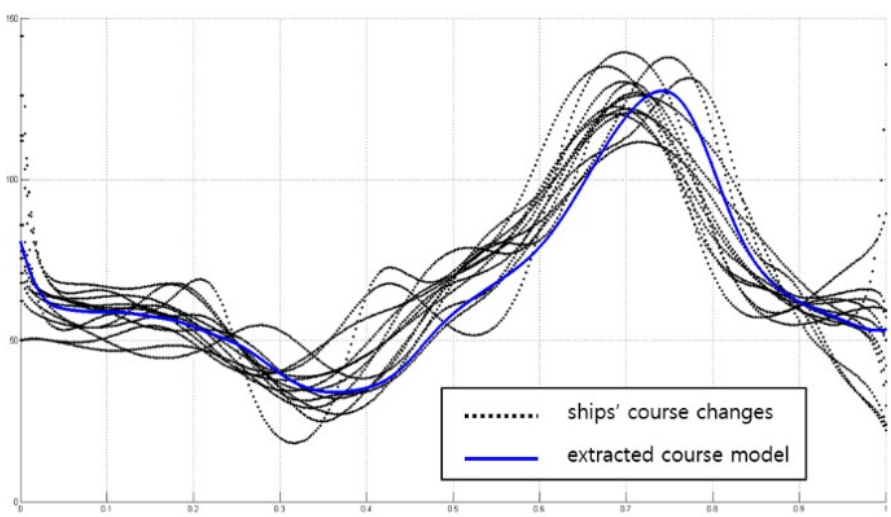

(c) Course changes and extracted course model

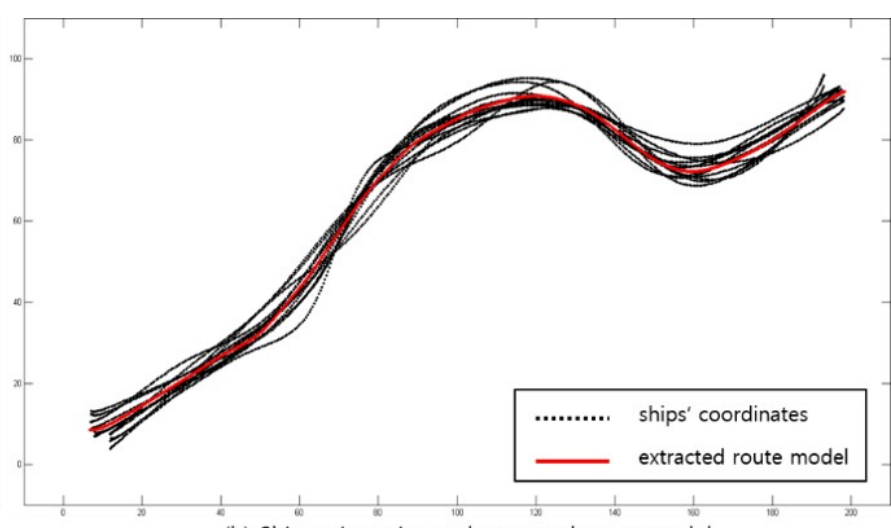

(b) Ship trajectories and extracted route model

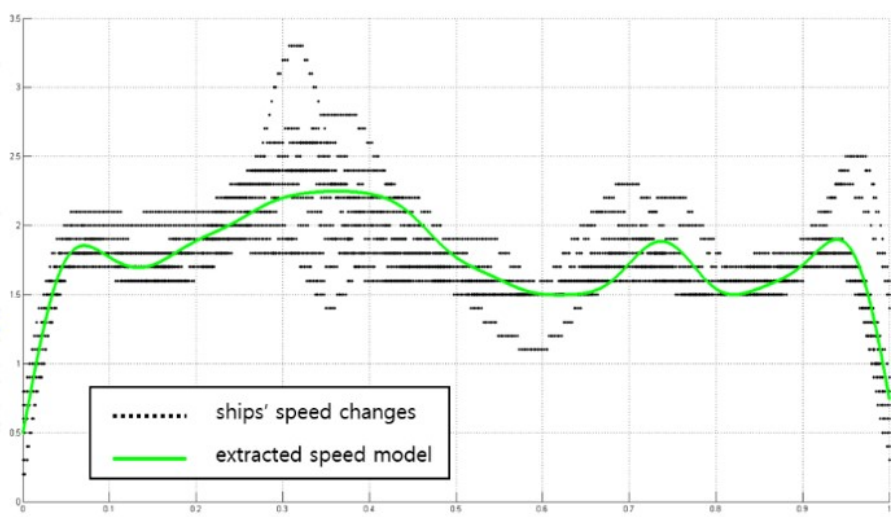

(d) speed changes and extracted speed model

Figure 4. Navigational data of simulation vessels; (a) ship trajectories and designated route, (b) ship trajectories and extracted route model, (c) course changes and extracted course model, (d) speed changes and extracted speed model.

calculation method, since the position is estimated based on the current speed and course of the ship, the error becomes larger as the position estimating time becomes longer. On the other hand, in the proposed DRP calculation method, it is possible to estimate the position stable because the calculation is based on the predicted trajectory, speed, and course. Table 2 shows the calculation result of position error between the actual ship's position and the calculated DRPs every 10 minutes. The proposed DRP calculation method shows more stable and accurate results.

In the second simulation, we compared the CPA calculation of the traditional method with that of the proposed method when the two vessels approaching each other. The ships to be simulated were arbitrarily selected from the data sets used for the traffic model extraction. Assuming a vessel B departing in the opposite direction to the vessel A entering along the sailing section, the assumption is made that the two vessels cross each other at the point $\mathrm{P}$ where the two vessels meet. In order to compare the accuracy of the DRP calculation, we compared the DRP calculations by the traditional calculation method and the
Table 2. Differences between DRP and actual position against target position

\begin{tabular}{ccc}
\hline $\begin{array}{c}\text { Time remained to } \\
\text { target point (min) }\end{array}$ & $\begin{array}{c}\text { Traditional DRP } \\
\text { calculation }\end{array}$ & $\begin{array}{c}\text { Proposed DRP } \\
\text { calculation }\end{array}$ \\
\hline 60 & 137.3387 & 2.8601 \\
50 & 11.2022 & 2.9185 \\
40 & 97.3620 & 2.8474 \\
30 & 88.6819 & 3.0770 \\
20 & 18.5178 & 2.8515 \\
10 & 16.4362 & 2.8716 \\
\hline
\end{tabular}

DRP calculation result of the proposed method by calculating with the time variation of two ships at the present position of each of the vessels A and B. Experimental results show that the DRP calculation method reflecting the navigational data proposed in this paper can be reliably estimated more than the traditional DRP calculation method.

Table 3 shows the results of comparing the actual crossing point and errors every 5-minute intervals based on the starting 


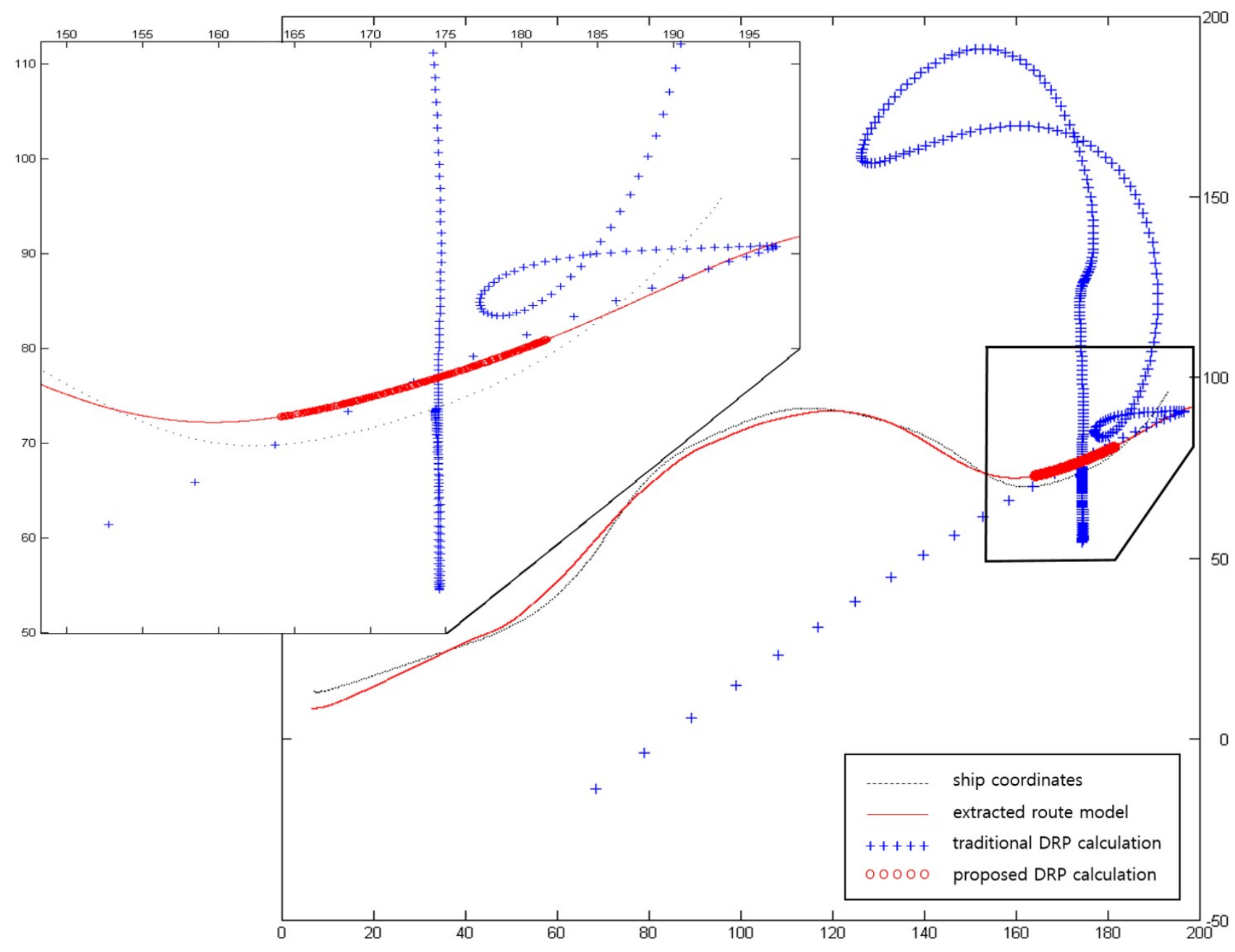

Figure 5. Comparison chart between traditional DRP calculation and proposed method.

Table 3. CPA calculation comparison of traditional and proposed methods

\begin{tabular}{ccc}
\hline $\begin{array}{c}\text { Time remained to } \\
\text { target point }(\mathrm{min})\end{array}$ & $\begin{array}{c}\text { Traditional CPA } \\
\text { calculation }\end{array}$ & $\begin{array}{c}\text { Proposed CPA } \\
\text { calculation }\end{array}$ \\
\hline 30 & 72.1134 & 1.3427 \\
25 & 9.2493 & 1.3543 \\
20 & 40.6132 & 1.1527 \\
15 & 29.1077 & 1.2063 \\
10 & 17.9055 & 1.1097 \\
5 & 5.1909 & 1.2512 \\
\hline
\end{tabular}

point of both ships. As a result, the performance of the proposed method is more accurate than traditional method. Figure 6 shows the cumulative result of the position estimating at unit time intervals every minute.

On the other hand, Figure 7 shows the result of comparing the CPA calculation changing from the current position of both ships to the final encountering point $\mathrm{P}$ while moving two vessels and the nearest distance at the estimated position based on the extracted traffic model. As shown in Figure 7, the error of CPA calculation gradually decreases with time. As the distance between the two vessels becomes closer, the error occurs until the time when the speed and the course are kept constant. On the other hand, the proposed calculation showed a fairly stable performance for the CPA calculation results. There is error only with the difference between the learned speed and the current speed.

\section{Conclusion}

At the time that a ship is in traffic with another ship, the decision maker of the navigation shall identify the intention of the other vessel for determining the action to be taken against the collision. In particular, the position estimating of own ship and the relative vessel is an important factor in such decision 


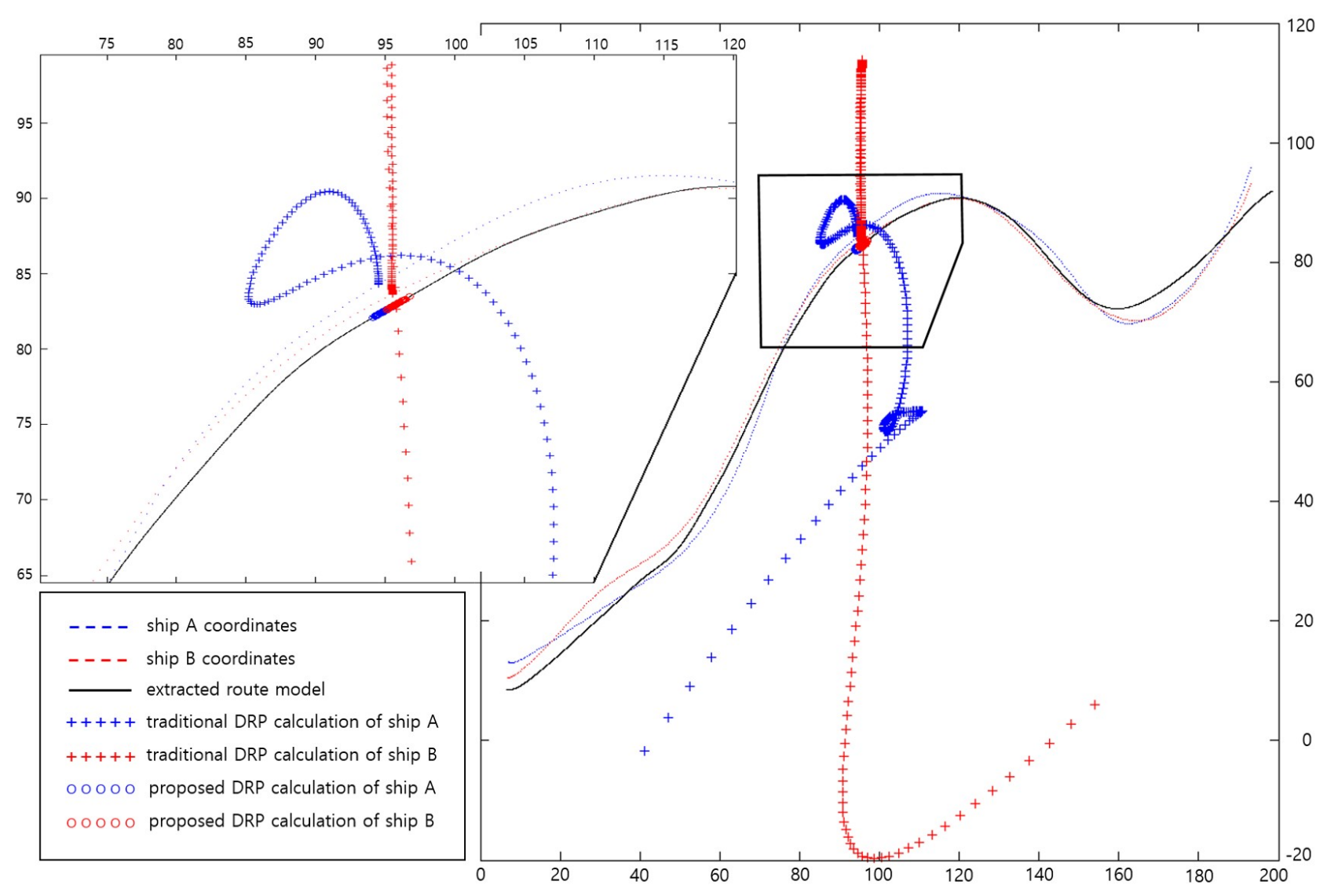

Figure 6. Comparison chart between traditional DRP calculation and proposed method of two approaching ships.

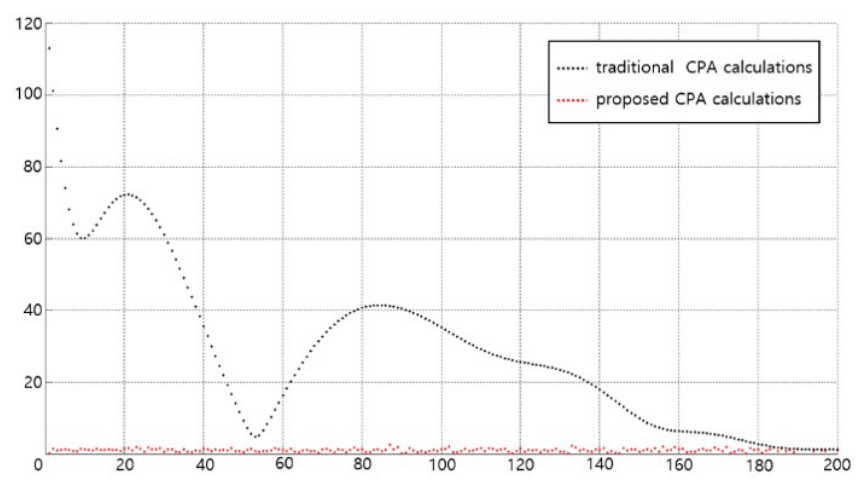

Figure 7. CPA comparison between traditional CPA calculation and proposed method.

making. In the traditional DRP calculation, since the position of the ship is predicted based on the current position, speed and course of the ship, there is a disadvantage that the reliability is significantly lowered in the waters where the ship is sailing along the route within harbor limit or approaching areas. In this study, we predicted the ship's traffic route and position based on the SVR seaway model that proposed previously. Based on the method of extracting ship's traffic route proposed in the SVR seaway model, the position and speed data of the vessel are learned, and the predicted position and speed are applied to the SVR seaway model. In order to verify the proposed DRP calculations, we constructed virtual path and ships' trajectories similar to the actual navigational environment. As a result we predicted the positions of the ship and presented the comparison result between the existing DRP calculation and proposed calculation. In addition, we verified the performance by comparing the results of the existing CPA calculation method and the proposed method for two vessels facing each other.

Since the DRP calculation and the CPA calculation by the proposed position estimating method are changing according to the learned traffic model and the sailing speed, the CPA is limited to the closest point on each traffic model. In the case of passing through the closest point, the new CPA will be the closest point on the next order. Therefore, the closest distance represents the encounter point according to the changing time on the route that two ships are expected to navigate. In conclu- 
sion, it can be seen that the traditional DRP and CPA calculation method shows a significant difference from the trajectory of the actual ship sailing because it cannot apply the change of the ship's course and speed in the future. Therefore, the traditional CPA and DRP calculation method can be used as effective information when navigating a straight section with a constant speed and course such as navigation in the open sea or in the ocean. As the result of the simulation, the DRP and CPA calculation method proposed in this paper, which estimates the position based on the change of the navigational data is more reliable. However, in the proposed method, when two vessels gradually approach and navigate, data correction is required according to the change of the ship's position or other navigational data due to avoidance of collision. This is because if there is a significant deviation, an error occurs in the forecasting of the two ships. In this case, it is necessary to calibrate the reference route through monitoring the data on the ship's route and correcting the position accordingly. In addition, the limitation of this study is that the results of position estimation may be inaccurate if the speed and the course are unstable such as the case of berthing and un-berthing operation.

\section{Conflict of Interest}

No potential conflict of interest relevant to this article was reported.

\section{References}

[1] International Maritime Organization, Strategy for the Development and Implementation of e-Navigation, London: International Maritime Organozation, 2009.

[2] T. Hong, "Development of a system for transmitting a navigator's intention for safe navigation," International Journal of Fuzzy Logic and Intelligent Systems, vol. 14, no. 2, pp. 130-135, 2014. http://dx.doi.org/10.5391/ijfis. 2014.14.2.130

[3] J. S. Jeong, K. I. Kim, and G. K. Park, "A quantitative collision probability analysis in port waterway," Journal of Korean Institute of Intelligent Systems, vol. 22, no. 3, pp. 373-378, 2012. http://dx.doi.org/10.5391/jkiis.2012. 22.3 .373

[4] K. I. Kim, J. S. Jeong, and G. K. Park, "Assessment of external force acting on ship using big data in maritime traffic," Journal of Korean Institute of Intelligent Systems, vol. 23, no. 5, pp. 379-384, 2013. http://dx.doi.org/10. 5391/jkiis.2013.23.5.379

[5] International Maritime Organization, Resolution A.857 (20): Guidelines for Vessel Traffic Services. London: International Maritime Organization, 1997.

[6] Korea Ministry of Government Legislation, Act of Ship Arrival and Departure (Law No. 13265), 2015.

[7] Korea Ministry of Government Legislation, Maritime Safety Law (Law No. 13386), 2015.

[8] Korea Ministry of Public Safety and Security, Vessel Traffic Service Operational Manuals (No. 135), 2015.

[9] N. Bowditch, The American practical navigator: an epitome of navigation, 2012; Available http://www.1yachtua com/nauticalcharts/downloads/Practical_navigator.pdf

[10] J. S. Kim, J. S. Jeong, and G. K. Park, "Utilization of planned routes and dead reckoning positions to improve situation awareness at sea," International Journal of Fuzzy Logic and Intelligent Systems, vol. 14, no. 4, pp. 288-294, 2014. http://dx.doi.org/10.5391/ijfis.2014.14.4.288

[11] J. S. Kim and J. S. Jeong, "Pattern recognition of ship navigational data using support vector machine," International Journal of Fuzzy Logic and Intelligent Systems, vol. 15, no. 4, pp. 268-276, 2015. http://dx.doi.org/10.5391/ IJFIS.2015.15.4.268

[12] J. S. Kim and J. S. Jeong, "Extraction of reference seaway through machine learning of ship navigational data and trajectory," International Journal of Fuzzy Logic and Intelligent Systems, vol. 17, no. 2, pp. 82-90, 2017.

[13] V. N. Vapnik, The Nature of Statistical Learning Theory, Now York: Springer, N.Y, 1995.

[14] V. N. Vapnik, Statistical Learning Theory,New York: John Wiley \& Sons, 1998.

[15] S. R. Gunn, "Support vector machines for classification and regression," School of Electronics and Computer Science, University of Southampton, UK, 1998.

[16] H. Y. Han, Introduction to Pattern Recognition, Seoul: HANBIT Academy Inc., 2014. 
[17] C. W. Hsu, C. C. Chang, and C. J. Lin, "A practical guide to support vector classification," Department of Computer Science, National Taiwan University, Taipei, Taiwan, 2003.

[18] J. S. Kim, J. S. Jeong, and G. K. Park, "Prediction table for marine traffic for vessel traffic service based on cognitive work analysis," International Journal of Fuzzy Logic and Intelligent Systems, vol. 13, no. 4, pp. 315-323, 2013. http://dx.doi.org/10.5391/ijfis.2013.13.4.315

[19] J. S. Kim, "A design of reference route model based on SVR through reconstruction of ship trajectories in VTS area," PHD dissertation, Mokpo National Maritime University, Mokpo, 2016.

[20] M. R. Benjamin, J. J. Leonard, J. A. Curcio, and P. M. Newman, "A method for protocol-based collision avoidance between autonomous marine surface craft," Journal of Field Robotics, vol. 23, no. 5, pp. 338-339, 2006.

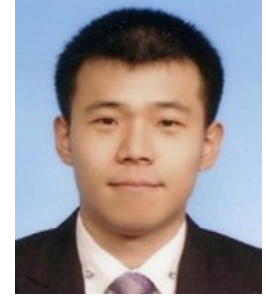

Joo-Sung Kim is a vessel traffic services operator at Kyeong-In VTS Center in Korea. His research interests include maritime traffic engineering, ship collision avoidance, maritime information and communication network. He received his B.S. degree in Nautical Science from Mokpo National Maritime University in Korea in 2004, his M.S. degree in International Maritime Transportation Sciences from Mokpo National Maritime University in Korea in 2014 and his Ph.D. degree in International Maritime Transportation Sciences from Mokpo National Maritime University in Korea in 2016. His research areas include intelligent system, fuzzy system, human factors engineering, work analysis, vessel traffic services, maritime transportation system, etc.

E-mail: jskim81@korea.kr 